\title{
PROJETO CORPORE: EDUCAÇÃO EM SAÚDE E PREVENÇÃO AOS TRANSTORNOS ALIMENTARES
}

\author{
E. C. S. Penas ${ }^{1} \&$ J. B. Dantas ${ }^{2}$
}

${ }^{1}$ Bolsista do projeto de extensão "Corpore: por uma prática multiprofissional de prevenção aos transtornos alimentantes" e graduanda pela Universidade Federal do Ceará (UFC). E-mail: evelyn.sousapenas @ gmail.com; ${ }^{2}$ Coordenadora do projeto de extensão "Corpore: por uma prática multiprofissional de prevenção aos transtornos alimentantes" e Professora Adjunta do Departamento de Psicologia da Universidade Federal do Ceará (UFC. Email: juremabdantas@gmail.com

Artigo submetido em Setembro/2017 e aceito em Setembro/2017

\section{RESUMO}

O Projeto Corpore: por uma prática multiprofissional de prevenção aos transtornos alimentares, vinculado ao Laboratório de Estudos em Psicoterapia, Fenomenologia e Sociedade - LAPFES tem como objetivo propiciar um serviço multidisciplinar efetivo na prevenção de transtornos alimentares junto à comunidade. Suas ações ocorreram, primeiramente, na Clínica Escola de Psicologia da UFC no período de março de 2016 a julho de 2017, com atendimentos individuais e em grupo por estagiários e extensionistas de psicologia e nutricionistas voluntários. No segundo semestre de 2017, as atividades foram estendidas ao contexto escolar, buscando trabalhar a problemática da construção da autoimagem com adolescentes de uma escola pública estadual da cidade de Fortaleza - CE. O projeto com esta ação em saúde para o público jovem, maior grupo de risco para o desenvolvimento de transtornos da imagem corporal, consolida a relação da universidade com a população em geral, sobretudo, ofertando um serviço público de qualidade vocacionado à prevenção primária e promoção de saúde.

PALAVRAS-CHAVE: Autoimagem. Prevenção. Educação em Saúde. Transtornos alimentares.

\section{CORPORE PROJECT: EDUCATION IN HEALTH AND PREVENTION OF FOOD DISORDERS}

\begin{abstract}
The Corpore Project: a multiprofessional practice for the prevention of eating disorders, linked to the Laboratory of Studies in Psychotherapy, Phenomenology and Society - LAPFES, aims to provide an effective multidisciplinary service in the prevention of eating disorders in the community. His actions took place, first, at the UFC Clinical School
\end{abstract}

of Psychology from March 2016 to July 2017, with individual and group visits by trainees and extensionists of psychology and volunteer nutritionists. In the second half of 2017, the activities were extended to the school context, seeking to work on the issue of self-image construction with adolescents from a state public school in the city of 
Fortaleza - CE. The project with this action in health for young people, a major risk group for the development of body image disorders, consolidates the relationship of the university with the general population, above all, offering a quality public service aimed at primary prevention and promotion of health.

KEYWORDS: Self image. Prevention. Health Education. Eating Disorders.

\section{INTRODUÇÃO}

O cenário contemporâneo coloca novamente a questão do corpo em cena, entretanto, hoje isso ocorre de modo diferente do que se pode ver em outras épocas. Vive-se à luz de uma série de exigências, a fim de valorizar as formas corporais e a aparência como fator importante de reconhecimento e distinção social. A cultura contemporânea que, segundo Lipovetsky (2004), é marcada pela urgência, pelo excesso, pelo imediatismo, pelo avanço técnico-científico, pelo hiperconsumo, pelo hedonismo excessivo, coloca aos indivíduos a imposição de se adequar a certos padrões estéticos corporais. Nesse terreno, o corpo tem se configurado cada vez mais como um dos principais espaços simbólicos na construção dos modos de subjetividade de nossa época. Neste contexto em que o corpo se torna polo de preocupação e investimento, parece-nos que a questão da autoimagem e sua intrínseca relação com o culto ao corpo se mostra como um tema fundamental de discussão para o campo da Psicologia. Passaram-se os anos e a inserção das tecnologias no nosso dia-a-dia fez com que a estética e a construção do corpo mudassem consideravelmente. A relação com nosso corpo parece estar sendo radicalmente modificada pelo fácil acesso a diversos recursos ligados à boa forma, criando certa exaltação e supervalorização do corpo.

Refletindo sobre os atravessamentos da sociedade na experiência corporal do sujeito contemporâneo e a possibilidade de sofrimento relacionado à vivência do corpo, criou-se o "Projeto Corpore: por uma prática multiprofissional de prevenção aos transtornos alimentares", projeto de extensão multidisciplinar do LAPFES - Laboratório de Estudos em Psicoterapia, Fenomenologia e Sociedade, vinculado ao Departamento de Psicologia da Universidade Federal do Ceará - UFC, que iniciou suas atividades no primeiro semestre letivo de 2016 na Clínica Escola de Psicologia da UFC. O projeto tem como objetivo principal ofertar um serviço efetivo de prevenção aos transtornos alimentares junto à comunidade por meio de um atendimento integral e multiprofissional. Sua idealização foi um 
desdobramento da pesquisa desenvolvida pelo mesmo laboratório: "O corpo e seus dilemas: uma discussão sobre a construção da autoimagem na contemporaneidade", que ocorreu de 2015 a 2017 e que se debruçou sobre o fenômeno do culto ao corpo ou corpolatria e suas implicações no processo de construção da autoimagem na atualidade. As discussões sobre a temática trouxeram à tona a reflexão acerca do possível sofrimento relacionado à autoimagem, em um contexto de fortes exigências com a aparência, o que despertou o interesse em trabalhar com pessoas que tivessem algum tipo de insatisfação com a autoimagem ou mesmo distorções da imagem corporal. Os membros do projeto fundamentam sua prática clínica em uma perspectiva fenomenológico-existencial a partir da fenomenologia enquanto método e dos pressupostos teóricos baseados em conceitos apresentados por filósofos da existência como Jean-Paul Sartre e Martin Heidegger.

Considerando que a insatisfação corporal, de acordo com Andrade (2000), aliada às práticas inadequadas de controle de peso e comportamentos alimentares anormais, pode desencadear o que chamamos de transtornos do comportamento alimentar, este projeto de extensão pode se constituir como um estudo de prevenção aos transtornos alimentares. Em sua nova fase, desenvolvida a partir do segundo semestre de 2017 , o projeto busca trabalhar em uma perspectiva de educação em saúde no âmbito de uma escola de Ensino Médio da cidade de Fortaleza com adolescentes com faixa etária entre 14 e 18 anos, marcando seu caráter de prevenção aos transtornos alimentares e as chamadas patologias da imagem corporal.

\section{POSSIBILIDADE OU IMPEDIMENTO: QUANDO O CORPO SE TORNA PROBLEMA?}

Diversos estudiosos tomaram o corpo como objeto de reflexão ao longo da história da humanidade. Entretanto, vê-se, no contemporâneo, traços próprios da nossa época que atravessam a experiência corporal. Como afirmam Cassimiro, Galdino e Sá (2012, p. 64) "o corpo é um elemento de expressão cultural", assim, não é apenas materialidade, mas onde se encarnam as experiências em um dado contexto. O que marca a relação homem e mundo é o seu corpo. Enquanto corpo cultural, atravessado por fatores sociais, econômicos, políticos e 
culturais, vale salientar algumas características do contexto da hipermodernidade (LIPOVETSKY, 2004) que perpassam a vivência do corpo nesses tempos, tais como o excesso, a urgência, a aceleração, o imediatismo, o hiperconsumo e a crença exacerbada na tecnologia.

No cenário contemporâneo, o corpo tem ganhado grande relevância, figurando como objeto que pode (e deve) ser consumido, modelado, esculpido e exibido. Aproximar-se do corpo dito ideal se torna fonte de reconhecimento e distinção social. Nessa lógica, aqueles que não alcançam o que se deseja: o corpo jovem, magro, "sarado" e performático, isto é, aqueles que não são capazes de sequer de controlar o próprio corpo são dignos de repúdio, de exclusão. Sibilia (2010) nos aponta que “[...] nem todos os corpos são igualmente idolatrados. Nem todas as figuras humanas suscitam idêntica reverência, e nem todas são veneradas com a mesma afeição. O culto ao corpo da sociedade contemporânea é, na verdade, um culto a um certo tipo de corpo.” (2010, p. 198). Mattos (2014) coloca ainda que na contemporaneidade o corpo foi espetacularizado e o discurso atual não trata do corpo ou organismo, como fora na modernidade, mas sobre a imagem, corroborando com Debord (1997) que ressalta o valor contemporâneo atribuído à aparência. O indivíduo parece ser responsável por sua aparência física por meio das várias formas de construções corporais hoje presentes no mercado - como as dietas, os exercícios físicos, os variados tratamentos de beleza e as cirurgias plásticas. E, assim, o corpo atual, ou seja, aquele que se encontra em consonância com os padrões de beleza contemporâneos que associam juventude, beleza e saúde apresenta-se como um valor fundamental na sociedade ocidental. Estamos assistindo a enunciação de um corpo espetacularizado. Estamos diante não mais da valorização do corpo, mas sim da aparência corporal.

Podemos considerar que a valorização do corpo vem se tornando o imperativo do viver contemporâneo. O culto ao corpo se mostra como característica de nossa época e encontra-se assentado na busca diária por um corpo perfeito capaz de superar qualquer problema e corresponder qualquer expectativa. Visto pelos meios de comunicação como algo que pode ser manipulado ou modificado, o corpo vem se tornando polo dos mais profundos desejos e um grande objeto de investimento. $\mathrm{O}$ vício da perfeição contracena, absurdamente, com o aumento da incidência do excesso de peso em todos os estratos etários e dos 
transtornos alimentares. A sociedade dos paradoxos procura neutralizar as heterodoxias, elegendo o corpo como critério de identidade e palco de excentricidades. Nessa (des)ordem, emergem as psicopatologias alimentares como translações do mal-estar contemporâneo e que convocam aos profissionais de saúde para uma ampliação do olhar, implicado, até mesmo, sobre as formas de representação da autoimagem, que converge na produção de um cuidado integral e minimamente genuíno. Discutir a relação que estamos construindo com o nosso corpo na atualidade e, sobretudo, como estamos construindo nossa autoimagem é a preocupação central deste projeto de extensão voltado aos cuidados necessários à prevenção dos transtornos alimentares.

Segundo Ferreira (2011), na atualidade não se trata mais de um controle disciplinar do social através de aparelhos repressivos, mas sim de uma diversidade de formas de sedução que tornam beleza e juventude o novo conceito que significa o estatuto do corpo. $\mathrm{O}$ uso de certas práticas na procura de um corpo ideal, que seja performático, quase inumano, em vista da constante busca pela perfeição, faz com que aprisionados nas malhas da tecnologia, o homem distancie-se cada vez mais da vida com ela é, utilizando-se do que é artificial, controlado, manipulado para alcançar o objetivo de um corpo perfeito. A relação com o corpo é expressa de diversos modos. Um deles é o comportamento alimentar e a forma que nos relacionamos com a alimentação, atravessado pela imagem corporal que os indivíduos têm de si. Tendo em vista que buscamos atuar na prevenção dos transtornos alimentares, cabe pontuar que diversos fatores atuam sobre o comportamento alimentar, tais como, autoimagem, necessidades fisiológicas, saúde individual, preferências e desenvolvimento psicossocial e social como hábitos familiares, amigos, valores e regras sociais e culturais, mídia, modismos, experiências e conhecimentos. Vale ressaltar que durante a adolescência a percepção da imagem corporal desencadeia grande parte dos comportamentos alimentares anormais (REATO et. al., 2007).

A insatisfação com o próprio corpo, segundo Freitas e Freitas (2014), é um dos primeiros sinais dos transtornos alimentares, expressa de diversas formas, seja através de dietas, exercícios físicos exacerbados, vergonha do próprio corpo ou outras formas de descontentamento com a imagem corporal. É importante destacar a gravidade dessa condição, que dentre os transtornos psiquiátricos, é aquele que mais leva a óbito. Entretanto, como é 
possível não se sentir insatisfeito em uma sociedade que estabelece padrões cada vez mais distantes do que é possível alcançar? Desse modo, reconhecemos o cenário contemporâneo como solo fértil para o desenvolvimento de tais acometimentos psicopatológicos e a importância de investir em ações que visem à discussão sobre a temática, principalmente com o público adolescente.

\section{MATERIAIS E MÉTODOS}

Em seu início, no ano de 2016, antes dos atendimentos em grupo começarem a funcionar, realizou-se a divulgação do projeto através de redes sociais, panfletos e cartazes afixados em locais públicos com grande circulação de pessoas, incluindo outras instituições públicas de saúde. Posteriormente, foram realizadas as inscrições via e-mail e na própria Clínica de Psicologia da UFC, local no qual ocorreram os atendimentos. Os interessados foram contatados e convidados para uma entrevista de triagem realizada por estagiários com o apoio de extensionistas. Realizou-se também busca ativa de possíveis interessados no projeto a partir das pessoas já inscritas e/ou triadas na Clínica Escola. Aqueles que chegaram ao projeto por meio da divulgação nas redes sociais, foram inscritos e após as triagens, foram encaminhados ao projeto aqueles que atenderam ao perfil e tiveram interesse no atendimento em grupo. Houve alguns casos em que, ao passar pela triagem, o encaminhamento realizado foi à psicoterapia individual, preferencialmente com os estagiários participantes do projeto.

Os atendimentos começaram sendo realizados por estagiários e extensionistas de psicologia e, ao longo do processo, duas nutricionistas se voluntariaram a participar do projeto. $\mathrm{O}$ grupo teve frequência semanal e foi facilitado por três terapeutas, estagiários e extensionistas do laboratório, estudantes da UFC e de outras instituições de ensino superior, em caráter voluntário. Também foram realizados quinzenalmente encontros de supervisão com a professora coordenadora do projeto. Além disso, foram ofertados atendimentos por uma nutricionista voluntária aos pacientes que tiveram interesse, não sendo condição para participação no projeto ter orientação nutricional. No primeiro semestre do projeto, os atendimentos da nutrição ocorreram em dois formatos, individualmente e em grupo, focando na mudança de hábitos alimentares, na relação com a alimentação e não propriamente no ganho ou perda de peso. Posteriormente, os atendimentos nutricionais ocorreram apenas em 
grupo, por perceber que os usuários tinham dificuldade de comparecer em dois momentos distintos.

Em geral, o público era composto por pessoas da comunidade em geral, com demandas envolvendo possíveis distorções da autoimagem, insatisfação com a imagem corporal e problemas de autoestima, porém sem transtornos alimentares já instaurados. Os atendimentos em grupo possuíam tanto o caráter psicoterapêutico quanto psicoeducativo, com a participação de profissionais de diversas áreas para discutir temas pertinentes à temática do grupo, de acordo com o interesse dos participantes. Ao longo do processo, utilizou-se como recursos textos, vídeos, dinâmicas de grupo para trabalhar as temáticas emergidas. A não utilização de métodos de avaliação quantitativos se justifica pelo referencial teóricometodológico da fenomenologia-existencial, pois não é possível mensurar os aspectos da experiência vivida por meio de testes padronizados.

\section{RESULTADOS E DISCUSSÕES}

O projeto Corpore, em suas ações e intervenções até o presente momento, vem proporcionando um espaço de acolhimento no qual torna-se possível o compartilhamento de experiências, com o intuito de facilitar o processo de ressignificação de questões relacionadas ao corpo e a autoimagem como um todo. O projeto trabalha no tripé constitutivo da autoimagem: como o sujeito se percebe; como o outro o percebe e como ele percebe o outro. É importante também ressaltar o diferencial do atendimento multiprofissional que contribuiu para o melhor resultado na evolução das pessoas atendidas. Além disso, buscou-se estabelecer uma rede de apoio para possíveis encaminhamentos de pessoas com patologias já estabelecidas, tais como o Centro de Tratamento de Transtornos Alimentares - CETRATA, vinculado ao Departamento de Medicina Clínica da UFC e o Programa Interdisciplinar de Nutrição aos Transtornos Alimentares e Obesidade - PRONUTRA, vinculado a Universidade de Fortaleza - UNIFOR, ambulatórios especializados nesses tipos de transtorno.

No primeiro semestre de funcionamento do grupo houve, em média, 8 participantes, sendo a maioria do sexo feminino permanecendo até o final apenas as mulheres. Em geral, a maior parte era assídua, mas ocorreram episódios em que todos faltaram ou apenas uma 
participante compareceu ao encontro. Foram realizados ao longo do semestre 12 encontros. Três destas participantes tiveram interesse em continuar no grupo do próximo semestre. Surgiram no discurso dos integrantes algumas temáticas recorrentes: o julgamento do outro; a relação com o alimento e ansiedade; o modo que elas viam o corpo e como isso interferia na maneira de se relacionar, incluindo ambiente de trabalho e relações afetivas. Notou-se bastante identificação entre os participantes a partir dos temas trazidos.

No segundo semestre manteve-se a média de participantes, com alguns integrantes novos, incluindo membros do sexo masculino, havendo apenas duas desistências ao longo do processo. No decorrer dos atendimentos do grupo emergiram novos pontos que foram tematizados, tais como: a necessidade de ser escutado sem julgamentos, diferente de outros contextos que vivenciam; a dificuldade de expressar os sentimentos, muitas vezes sendo expostos por meio de textos; a exigência por tentar corresponder às expectativas próprias e dos outros; o medo do julgamento das outras pessoas e como isso acaba por influenciar na privação de algumas experiências; a não possibilidade de prever e controlar o futuro; os sentidos sobre as relações interpessoais; o medo da solidão e de ficar na própria companhia e a possibilidade de abrir-se a novas experiências. Todos os participantes que permaneceram até o final do grupo tiveram interesse em continuar o processo no semestre seguinte. Na avaliação houve a sugestão de trazer atividades dirigidas como dinâmicas e textos que possibilitem a discussão sobre a temática do corpo de forma mais aprofundada. O feedback dos participantes foi bastante positivo em ambas as experiências.

Após um ano de existência, em 2017, o projeto foi contemplado com uma bolsa da Pró-Reitoria de Extensão da UFC (PREX), dada sua pertinência e pioneirismo no Estado do Ceará no atendimento a esse público. Assim, no terceiro semestre participaram 4 pessoas maiores de 18 anos, de ambos os sexos, com Ensino Superior Incompleto ou Completo. Em alguns encontros foram levadas atividades disparadoras, textos ou vídeos para suscitar discussões pertinentes com os conteúdos trazidos pelos participantes nos atendimentos anteriores. Tornou-se comum também que alguns participantes trouxessem textos da própria autoria ou que de alguma forma falassem sobre algo que gostariam de debater e compartilhar com os demais participantes. Os atendimentos com a nutricionista ocorriam duas vezes ao mês e eram discutidas temáticas pedidas pelos participantes do grupo como alimentação 
saudável, transtornos alimentares, alimentos funcionais, dentre outros. Pessoas que participaram do grupo desde o início e que relatam a importância como momento de escuta, de reflexão sobre a questão da autoimagem, mas também aspectos e áreas da sua vida que estão relacionados a isso indiretamente e que podem ser trabalhados nesse espaço. Valorou-se em todas as experiências o envolvimento na elaboração de atividades contando com a participação dos próprios clientes, entendendo que esse era um espaço de privilégio das suas questões e que o seu engajamento era fundamental no processo.

Entretanto, nesse semestre as ausências dos participantes foram recorrentes, o que demandou da equipe uma reformulação do projeto. Após uma avaliação do processo realizado na Clínica Escola de Psicologia da UFC, e a constatação do alto índice de evasão no grupo psicoterapêutico, a equipe optou em trabalhar com o público adolescente que é o maior grupo de risco dos transtornos alimentares. Assim, no segundo semestre de 2017, o projeto se estendeu para o contexto escolar com a perspectiva de educação em saúde, ao levar para uma escola estadual de ensino profissionalizante da cidade de Fortaleza discussões sobre a construção da autoimagem no contemporâneo. A seleção da turma ocorreu de acordo com a compatibilidade de horário entre os membros do projeto e da turma na escola. Notou-se que a dinâmica escolar dificulta a realização de encontros semanais de caráter psicoterapêutico. Por isso, optou-se por realizar encontros educativos, com a presença de profissionais de outras áreas como Nutrição e Educação Física. Desse modo, neste semestre estão sendo realizados encontros quinzenais em uma das turmas de primeiro ano do Ensino Médio da referida escola, com a proposta de discutir temáticas pertinentes a esse público, elencadas com a participação dos estudantes por meio de um levantamento de interesses, tais como os padrões estéticos impostos socialmente, bullying, a exposição do corpo na mídia e outros assuntos que surjam durante os encontros.

As ações do projeto Corpore, especialmente no contexto escolar, visam atuar no nível de prevenção primária aos transtornos alimentares, utilizando estratégias de educação em saúde. De acordo com Oliveira e Gonçalves (2004, p. 761) "a educação em saúde, pela sua magnitude, deve ser entendida como uma importante vertente à prevenção, e que na prática deve estar preocupada com a melhoria das condições de vida e de saúde das populações”. Desse modo, o Projeto Corpore visa contribuir com a construção de uma clínica 
comprometida com a emergência de novos sentidos e possibilidades de ajuda a uma demanda cada vez mais crescente na contemporaneidade relacionada aos diversos modos de enunciação do sofrimento diante da imagem corporal.

\section{CONSIDERAÇÕES FINAIS}

São desconhecidos outros projetos que trabalham nessa perspectiva preventiva aos transtornos alimentares na cidade e até mesmo no estado, portanto, considera-se pertinente que estratégias semelhantes sejam implementadas em outras instituições, bem como o atendimento a crianças e adolescentes por perceber a importância de se trabalhar nessa fase crucial para o desenvolvimento humano. Destaca-se também o pioneirismo do projeto que vem se consolidando e pretende se tornar a médio e longo prazo tornar referência no Estado do Ceará. O diferencial do Projeto Corpore está no seu caráter preventivo, sendo o único até agora na cidade de Fortaleza que lida com questões que são anteriores ao desenvolvimento dos transtornos, como: anorexia, bulimia, vigorexia etc. Espera-se que a ação junto às escolas possa se consolidar e atingir um maior número de pessoas com as atividades desenvolvidas e a discussão e informação sobre essas temáticas.

A modalidade de atendimento em grupo possibilita também aos terapeutas a experiência nesse formato de atendimento clínico, além de contribuir para a diminuição do tempo na fila de espera do serviço, podendo atender mais pessoas diante da crescente demanda por atendimento psicológico na atualidade. Constitui-se também como objetivo do projeto promover a qualificação da formação dos discentes do curso de Psicologia; a discussão sobre possibilidades de atuação profissional adequada às demandas sociais da atualidade e, sobretudo, a problematização da noção de corpo e suas possíveis reverberações no surgimento das patologias da beleza, ao sofrimento humano na busca obsessiva por um corpo perfeito cujas práticas perversas de autocuidado são marcas da contemporaneidade. Práticas essas que podem limitar as possibilidades pessoais, sujeitando os indivíduos a uma lógica violenta de adequação nesse caminho de busca pela perfeição.

Por fim, considera-se que o projeto Corpore atua na prevenção primária e promoção de saúde com o público jovem. Além disso, propicia uma discussão sobre saúde mental no 
ambiente escolar e uma aproximação da universidade com a comunidade, que caracteriza, consistentemente, a experiência de extensão, buscando atingir o máximo de pessoas com o que é discutido e produzido no ambiente acadêmico, levando para fora dos muros da universidade e cumprindo um papel de transformação social.

\section{REFERÊNCIAS}

ANDRADE, A. C. Para além dos sintomas: a trilogia do desamparo no vivido de mulheres com transtornos do comportamento alimentar. 2000. 250p. Dissertação (Mestrado em Saúde Pública) - Departamento de Saúde Comunitária da Faculdade de Medicina de Fortaleza, Universidade Federal do Ceará, Fortaleza, 2000.

CASSIMIRO, E. S.; GALDINO, F. F. S.; SÁ, G. M. As concepções de corpo construídas ao

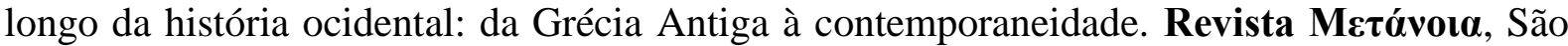
João del Rei, n. 14, 2012.

DEBORD, G. A sociedade do espetáculo: comentários sobre a sociedade do espetáculo. Rio de Janeiro: Contraponto, 1997.

FERREIRA, F. R. Ciência, arte e cultura do corpo: a construção de sentidos sobre o corpo a partir das cirurgias plásticas. Editora CRV, 2011, 185p.

FREITAS, S.; FREITAS, P. Imagem corporal nos transtornos alimentares e na obesidade. In: MATTOS, R. Imagem Corporal: Novos Olhares Numa Perspectiva Interdisciplinar Para o Século XXI. Rio de Janeiro: Paco Editorial, 2014.

LIPOVETSKY, G. Os tempos hipermodernos. São Paulo: Editora Barcarolla, 2004.

MATTOS, R. Imagem Corporal: Novos Olhares Numa Perspectiva Interdisciplinar Para o Século XXI. Rio de Janeiro: Paco Editorial, 2014.

REATO, L. F. N et. al. Hábitos alimentares, comportamentos de risco e prevenção de transtornos alimentares em adolescentes do Ensino Médio. Revista Paulista de Pediatria, vol. 25, núm. 1, março, 2007, pp. 22-26 Sociedade de Pediatria de São Paulo São Paulo, Brasil.

SIBILIA, P. Em busca da felicidade lipoaspirada: agruras da imperfeição carnal sob a moral da boa forma In: FREIRE FILHO, J. Ser feliz hoje: reflexões sobre o imperativo da felicidade. Rio de Janeiro: Editora FGV, 2010. 